In Implementing the new ELGs how do we create reading-rich environments in early years settings?

To be able to read is to hold the key to unlocking worlds of infinite possibility. Reading opens doors to information and knowledge but also to culture, imagination, fantasy and the inner minds of others. Reading together can bring pleasure, comfort, and in these days of social distancing due to Covid-19, increase feelings of connectedness and belonging. To be able to read is the right of every child.

In September 2021 the new Early Learning Goals (ELGs) for the Early Years Foundation Stage (EYFS, DfE,2017) become compulsory and practitioners will be working with the challenges and opportunities they present. The two new ELGs for Reading; (comprehension and word-reading), focus tightly on the development of specific and prescribed skills, including an explicit focus on phonics. This may give the impression that formal instruction is the most important vehicle for ensuring that children develop the reading skills they need. However, reading depends upon motivation as well as skills. Thankfully, the new Educational Programme for Literacy recognises that 'It is crucial for children to develop a life-long love of reading'. Therefore, in implementing the new ELGs, practitioners need to underpin their pedagogy with a reading-rich environment which nurtures children's intrinsic motivation, thereby optimising their reading potential.

\title{
What is Intrinsic Motivation?
}

Intrinsic motivation is distinguishable from that which is garnered by external rewards; for example, stickers, a desire to please others, or the completion of a reading scheme in record time. It refers to motivation from 'within'. In other words, reading is its own reward so that children actively want to engage with and feel 
interested and curious about books and reading. A century ago, John Dewey (1910, p.34) recognised curiosity as innate in children and he suggested that the educator's task was to "keep alive the sacred spark of wonder and to fan the flame that already glows". Early years practitioners are uniquely placed in education in that they work with the youngest children and so can protect and foster their innate curiosity. Psychologists, Deci and Ryan's (2017) ground-breaking work, identified three innate and universal conditions necessary for motivation. They argue that feelings of competence, autonomy and relatedness need to be present for motivation to endure. What might these look like in the context of early years' reading? They can be viewed as children feeling capable, free to make choices, and having a sense of belonging and connectedness with others.

\section{Competence (feeling capable)}

In its response to concerns raised by the profession regarding the proposed reforms to the ELGs, the Government acknowledged the link between language comprehension and later reading and writing. Children begin their literacy journey at birth and from the very start it is important to recognise and support their emergent skills which build the foundations of reading. These pre-reading skills include recognising patterns and meaning in speech, sounds and images. Talking to and singing regularly with babies and toddlers and inviting and praising their responses is vital. Repetition of favourite rhymes and songs fosters familiarity, and books with rhythm and repetition support recognition and enable participation, thus fostering feelings in children of pleasure and competence as they join in. Bruner identified the enactive stage of development in babies and toddlers, meaning that children's engagement with three-dimensional things precedes their understanding of icons (pictures) and symbols (text), so it is crucial that babies and toddlers engage with 
actual books. Books with sensory aspects, (textures, smells and interactive elements such as buttons to press) are particularly useful at this enactive stage as they invite exploration of the physical elements of books and emergent skills such as pageturning and physical orientation.

The new comprehension ELG emphasises reading to children and the introduction of new and challenging vocabulary. As children develop their speech, picture books are an essential resource to support the articulation of ideas, imagination, observations, predictions and questions and practitioners valuing children's responses helps build self-esteem and feelings of competence. Practitioners can use pictures as prompts to explore ideas and model new vocabulary.

As older children develop a sense of what they can and cannot do, they may be reluctant to engage with texts which they perceive as challenging. Respecting children's choices to revisit texts which are (too) easy for them is a valuable strategy as it can reignite or reinforce feelings satisfaction, pleasure and competence. Another useful strategy includes children making their own books. This invites children to regard themselves as authors, whose ideas are valuable and of interest to others.

\section{Autonomy (having a sense of choice)}

An environment rich with print and pictures, supports babies and toddlers' developing an understanding that icons and symbols convey meaning. If they are used to label accessible resources, pictures facilitate children in applying their understanding to make choices independently. Luke (ref) suggests that reading behaviours include the ability to act as a 'text critic' and as a 'text user'. In selecting (or rejecting) books children are acting as 'text critics' evaluating books and reading 
material, just as we adults do in making choices about what we read. In selecting specific books (for example, a cookery book in role play or a book to find out more about dinosaurs or transport), children engage with books for a purpose and thereby act as 'text users'. Practitioners can support these reading behaviours by ensuring direct accessibility to children, of a wide range of books with variation of purpose, including picture books, books with text, fiction and non-fiction, in inside and outside areas. What children choose may not correspond with practitioner preferences or expectations but the opportunity to realise personal preferences offers greater potential for richer and deeper language and vocabulary development as in their engagement, children think and talk about, explore and revisit their chosen books.

Giving children time to engage with reading behaviours independently, reinforces the idea that reading is valued and central to the ethos of the setting. Quieter spaces and physically comfortable environments also invite children to engage autonomously with books.

\section{Relatedness (Having a sense of belonging and connectedness)}

Sharing books and stories together one-to-one with babies and toddlers is a powerful way of strengthening emotional bonds. Physical proximity, eye contact and animated exchanges help to engender positive emotions. The adult is a potent role-model and when they show pleasure and delight in engagement with books, they reinforce positive messages about reading as an intrinsically rewarding activity.

For older children, the new Word-Reading ELG states that by the end of the EYFS children will:

-Say a sound for each letter in the alphabet and at least 10 digraphs; 
- Read words consistent with their phonic knowledge by sound-blending;

- Read aloud simple sentences and books that are consistent with their phonic knowledge, including some common exception words.

Every practitioner knows (and the principles of the EYFS acknowledge), that each child is unique and that children learn at different rates and in different ways so the prescriptive expectation of this new ELG presents a challenge. If children's motivation is lacking or extinguished, the challenge is made harder. Therefore, it's important that there are reading resources available to children which hold meaning for them i.e. that reflect children's social and cultural practices. For example, for many families reading online is the norm and some children will be much more familiar with a screen than a book. Similarly, children may be very familiar with characters from television and popular culture and be happy to engage with comics and non-traditional media to which they can more easily relate. Some reluctant readers are skilled users of technology and a screen can support their reading skills and also enable them to mentor their less computer-savvy peers, thereby increasing self-esteem, dialogue and feelings of connectedness.

Deeper dialogue with parents can provide insights into what children know about, care about and experience at home. In communications with parents it's secondnature for practitioners to share day-to-day information such as sleeping and eating routines and to report on children's learning, but sharing insights about children's personalities, fascinations and lived experiences can give finely-grained insights into them as individual personalities and help tailor more personalised responses. 
If we listen and respond to what children tell us themselves, we can better understand their perspectives, deepen our bonds with them and make the environment more meaningful to them. As an example, I remember speaking with a four-year-old from a farming family and asking him, "Are you going to be a farmer when you grow up?". He frowned at me and replied," I am a farmer". His rebuke provided me with a window into his world and his strong sense of identity. Gonzalez and Moll, (2005) use the term 'funds of knowledge' to describe the knowledge and understanding that children bring with them into settings, about which practitioners may be unaware. In seeking to uncover children's cultural realities, practitioners can better reflect children's worlds and provide reading resources which are more meaningful for them. A reading environment which acknowledges and celebrates that which is familiar to children supports their emotional security and wellbeing, helping to foster a sometimes elusive 'life-long love of reading'.

\section{Key points}

- Reading development requires both skills and motivation. Fostering children's intrinsic motivation supports the development of reading as an enduring habit

- Practitioners modelling engagement and pleasure in books and reading helps reinforce positive messages about reading as a rewarding activity.

- A reading-rich environment is also a language-rich environment where children feel competent and enjoy participating in familiar rhyming, rhythmic, songs and stories which support their emergent literacy skills

- Being able to make choices about what they read enables children to exercise literate behaviours including evaluating texts and reading for a purpose

- Covid-19 has resulted in the emotional and social needs of children being greater than ever and it is essential that every child can feel a sense of 
belonging and enjoy warm attachments with others. Sharing familiar and engaging books and stories helps strengthen emotional bonds.

\section{References}

Dewey, J. (1910). How we think. New York, Heath publishing Company

Gonzalez, N, Moll, LC, \& Amanti, C (eds) 2005, Funds of knowledge: theorizing practices in households, communities, and classrooms, Mahwah:Taylor \& Francis Group, Available from: ProQuest Ebook Central. [2 October 2020].

Luke, A. (2000). Critical literacy in Australia; a matter of context and standpoint. Journal of Adolescent and Adult literacy, 43(5): 448-61

Ryan, R.M. \& Deci, E.L. (2017). Self-determination theory: basic psychological needs in motivation, development and wellness. New York, Guilford Press

Smidt, S. (2011). Introducing Bruner. Oxon, Routledge

\section{Further reading and resources}

Letterpress project website: http://www.letterpressproject.co.uk/ 